Bangladesh J. Bot. 48(4): 1065-1073, 2019 (December)

\title{
ANTIOXIDANT AND ANTITYROSINASE ACTIVITIES OF MILKY WHITE MUSHROOM
}

\author{
Nuhu Alam*, Md Maniruzzaman Sikder, Md Abdul Karim ${ }^{1}$ \\ and Sheikh Mo Ruhul Amin \\ Department of Botany, Faculty of Biological Sciences, Jahangirnagar University, \\ Savar, Dhaka-1342, Bangladesh
}

Keywords: Antioxidant, Calocybe indica, Phenolic compounds, Tyrosinase inhibition, Xanthine oxidase

\begin{abstract}
It was intended to investigate the biological activities of different solvent extracts of the fruiting bodies of Calocybe indica ( $\mathrm{P} \& \mathrm{C}$ ). The bioactive compounds were extracted using acetone, methanol, and hot water. The antioxidant activities of three different extracts at $0.5-20.0 \mathrm{mg} / \mathrm{ml}$ of $C$. indica on $\beta$-carotene-linoleic acid ranged from $65.83-92.56,62.79-93.06$ and $61.42-92.12 \%$, respectively. The highest (2.825) reducing power inhibition was recorded in methanolic extract, while the lowest (2.332) was in hot water at the concentration of $8 \mathrm{mg} / \mathrm{ml}$. The free radicle scavenging activity was more pronounced in methanolic extract. Chelating effect of $C$. indica was significantly strong as compared to positive control. The xanthine oxidase and tyrosinase inhibitory activity of the acetone, methanol, and hot water extracts of $C$. indica increased with increasing concentration. Thirteen phenolic compounds i.e. biochanin-A, caffeic acid, chlorogenic acid, ferulic acid, formononetin, gallic acid, hesperetin, homogentisic acid, naringenin, naringin, protocatechuic acid, resveratrol and vanillin were detected from acetonitrile-hydrochloric acid extract. The result indicated that the maximum and minimum concentrations were recorded for gallic acid (29 $\mu \mathrm{g} / \mathrm{g})$ and formononetin $(10 \mu \mathrm{g} / \mathrm{g})$. Thus, it could be suggested that $C$. indica has the potential to be used as antioxidant and tyrosinase protection system of the human body against oxidative damage and other complications.
\end{abstract}

\section{Introduction}

Calocybe indica (P \& C), known as milky white mushroom, is popular in Bangladesh. It is prefered for its attractive white fruiting bodies as well as unique taste and flavor. On the other hand, low cost materials like agricultural wastes can be used as substrate for the production of this mushroom (Amin et al. 2010). Milky white mushrooms are rich in protein, edible fiber and minerals but lipid content is low. It is reported as therapeutic food as well as for preventing hypertension and hypercholesterolemia (Alam et al. 2008).

Edible mushrooms are good source of antioxidants that help to reduce oxidative damage in human body. Polyphenolic compounds have aptitude to scavenge free radicals by single-electron transfer. Thus, it is recognized as an excellent antioxidant (Diplock et al. 1998).

Xanthine oxidase (XO) is responsible for gout through the secretion of uric acid. Mushrooms have XO inhibitory actions with lesser side effects compared to uricosuric and anti-inflammatory agents. Thus, edible mushrooms are the source of such potential compounds (Zhou et al. 2001). In human physiology, melanin formatiom may be influenced by antioxidation, tyrosinase inhibition, and hormonal activities, etc. (Alam et al. 2012). Tyrosinase not only incorporates menalin production but also might be responsible for malignant cancer. Again, in whitening enhancement is due to the inhibition of tyrosinase activities (Sugimoto et al. 2004, Alam et al. 2011). Consequently, mushroom tyrosinase is popular among researchers due to its easy availability. In

*Author for correspondence: <mnabotju@yahoo.com>. ${ }^{1}$ Department of Botany, University of Dhaka, Dhaka-1000, Bangladesh. 
spite of the medicinal potential of $C$. indica has not been studied for its beneficial biochemical components. In addition, antioxidant activities, xanthine oxidase and and tyrosinase inhibitory properties of this mushroom are not available. Hence, the present investigation was undertaken to appraise the antioxidant, phenolic compound, xanthine oxidase activities and tyrosinase inhibitory effects with three different extracts of milky white mushroom.

\section{Materials and Methods}

Fresh fruiting bodies of Calocybe indica were collected from National Mushroom Development and Extension Centre (NAMDEC), Savar, Dhaka, Bangladesh. The fruiting bodies were dried through hot air at $40^{\circ} \mathrm{C}$ for $48 \mathrm{hrs}$ and pulverized. Five g of each powdered sample were mixed with $100 \mathrm{ml}$ of $60 \%$ aqueous acetone and $80 \%$ aqueous methanol stirring at $150 \mathrm{rpm}$ for $24 \mathrm{hrs}$ at $25^{\circ} \mathrm{C}$ to obtain acetone and methanol extracts. The extracts were filtered through two layers of Whatman No. 1 filter paper. To get a hot water extract the same quantity of sample was boiled at $100^{\circ} \mathrm{C}$ for $3 \mathrm{hrs}$ with $100 \mathrm{ml}$ deionized distilled water. The mixture was cooled at room temperature and filtered. The residues were then extracted with two additional $100 \mathrm{ml}$ aliquots of acetone, methanol, and deionized water, as described above. Then combined extracts were evaporated with a rotary evaporator (Eyela, Saitama, Japan) at $40^{\circ} \mathrm{C}$, and the remaining solvent was removed with a freeze-drier (Optizen, Daejeon, Korea). The yield from the 60\% acetone, $80 \%$ methanol and hot water extraction of $C$. indica was $24.84,26.44$ and $20.56 \%$ (w/w), respectively.

Antioxidant activity of each extract against $\beta$-carotene-linoleic acid of $C$. indica in four different concentrations i.e. $0.5,2.0,8.0$ and $20.0 \mathrm{mg} / \mathrm{ml}$ was determined according to the procedure described by Alam et al. (2012). Butylated hydroxytoluene (BHT) and $\alpha$-tocopherol (TOC) were used as positive controls at $0.5 \mathrm{mg} / \mathrm{ml}$ and a blank consisting of $0.5 \mathrm{ml}$ methanol. The mixture was measured by spectrophotometer (Optizen) at $490 \mathrm{~nm}$.

Four different concentrations such as $1,2,4$, and $8 \mathrm{mg} / \mathrm{ml}$ of acetone, methanol and hot water extracts of $C$. indica were used for the determination of reducing power according to the method of Gülçin et al. (2003). BHT and TOC were used as positive controls.

For the determination of DPPH radical scavenging activity, $0.125,0.25,0.5,1.0$, and $2.0 \mathrm{mg}$ $\mathrm{ml}^{-1}$ concentrations of acetone, methanol, and hot water extracts of $C$. indica were used according to the method of Cuendet et al. (1997). The absorbance of the resulting solution was measured at $517 \mathrm{~nm}$ using a spectrophotometer. BHT, TOC and L-ascorbic acid were used as positive controls.

Five different concentrations i.e. $0.63,0.125,0.250,0.5$ and $1.0 \mathrm{mg} / \mathrm{ml}$ of acetone, methanol and hot water extract of $C$. indica were used for the determination of chelating effect according to the method of Dinis et al. (1994). The absorbance of the solution was measured by spectrophotometer at $562 \mathrm{~nm}$. using BHT and TOC as positive controls.

Xanthine oxidase (XO) inhibitory activity in four different concentrations i.e. 0.5, 1.0, 2.0, 4.0, and $8.0 \mathrm{mg} / \mathrm{ml}$ of acetone, methanol, and hot water extracts from the fruiting bodies of $C$. indica was assayed spectrophotometrically under aerobic conditions according to the methods of Alam et al. (2012). Allopurinol was used as positive control, which was known as inhibitor of XO.

Tyrosinase inhibition activity in $0.125,0.250,0.5$, and $1.0 \mathrm{mg} / \mathrm{ml}$ concentration of acetone, methanol, and hot water extracts from the fruiting bodies of $C$. indica were measured by dopachrome method with L-DOPA as the substrate (Masuda et al. 2005). L-ascorbic acid and kojic acid were used as positive controls.

Two g powders of milky white mushrooms were extracted with $10 \mathrm{ml}$ of acetonitrile and $2 \mathrm{ml}$ of $0.1 \mathrm{~N}$ hydrochloric acid. Sample preparation for the phenolic compound analysis followed the method of Kim et al. (2008). Then $20 \mu \mathrm{l}$ filtrate was loaded onto an Agilent-1100 series HPLC system (Agilent Technologies, Waldbronn, Germany). Separation was achieved on a $250 \mathrm{~nm} \times 4.6$ 
mm i.d., $5 \mu \mathrm{m}$, YMC-Pack ODS AM (YMC Co. Ltd., Kyoto, Japan) column. Fifteen standard compounds such as biochanin-A, caffeic acid, (+) catechin, chlorogenic acid, ferulic acid, formononetin, gallic acid, hesperetin, homogentisic acid, naringenin, naringin, protocatechuic acid, pyrogallol, resveratrol and vanillin were used as standards. Detection was performed with a diode array detector at a wavelength of $280 \mathrm{~nm}$.

The data from all experimental findings have been expressed as means \pm standard deviations (Sd). Inter group differences were analyzed by one-way analysis of variance followed by DMRT. Differences were considered as significant at $\mathrm{p} \leq 0.05$.

\section{Results and Discussion}

$\beta$-carotene-linoleic acid from acetone, methanol and hot water extracts from the fruiting bodies of Calocybe indica ranged 65.83 - 92.56\%, 62.79 - 93.06\% and 61.42 - 92.12\%, respectively (Table 1). Similar results were recorded from the edible mushrooms, Leucopaxillus giganteus, Sarcodon imbricatus and Agaricus arvensis (Barros et al. 2007) and their antioxidant activities were $61.4,54.3$ and $46.7 \%$ at $5 \mathrm{mg} / \mathrm{ml}$, while antioxidant activity of positive control, tertiary butylhydroquinone (TBHQ) reached $82.2 \%$ at $2 \mathrm{mg} / \mathrm{ml}$ in methalone extract. The results suggested that the antioxidant activity on $\beta$-carotene-linoleic acid from the fruiting bodies of $C$. indica was highly promising as compared to those mentioned above. It is clear that the mushroom extracts reduced the $\beta$-carotene linoleate free radical and other free radicals, which is likely the result of volatile solvent extracts from several commercial and medicinal mushrooms (Mau et al. 2004).

Table 1. Antioxidant activity against $\beta$-carotene-linoleic acid at different concentrations of various extracts from the fruiting bodies of Calocybe indica.

\begin{tabular}{lcccc}
\hline Sample & \multicolumn{4}{c}{ Concentration $(\mathrm{mg} / \mathrm{ml})$} \\
\cline { 2 - 5 } & 0.5 & 2.0 & 8.0 & 20.0 \\
\hline Acetone extract & $65.83 \pm 0.24$ & $85.94 \pm 0.43$ & $89.02 \pm 0.32$ & $92.56 \pm 0.41$ \\
Methanol extract & $62.79 \pm 0.19$ & $80.25 \pm 0.24$ & $89.12 \pm 0.21$ & $93.06 \pm 0.24$ \\
Hot water extract & $61.42 \pm 0.45$ & $54.92 \pm 0.36$ & $83.62 \pm 0.23$ & $92.12 \pm 0.19$ \\
BHT & $95.21 \pm 0.17$ & - & - & - \\
TOC & $96.02 \pm 0.18$ & - & - & - \\
\hline
\end{tabular}

A value expressed as means $\pm \mathrm{Sd}(\mathrm{n}=3)$. -, not analyzed, BHT- butylated hydroxytoluene and

TOC - $\alpha$-tocopherol.

Table 2 shows the result of reducing power inhibition of $C$. indica in three different extracts at selective concentrations. The maximum reducing power inhibition (2.825) was recorded in methanol extract, while lowest (2.332) was observed in hot water extract at $8.0 \mathrm{mg} / \mathrm{ml}$ concentration. The results indicated that the reducing power inhibition of milky white mushroom is very low as compared to positive control, where the reducing power of BHT and TOC at 1.0 $\mathrm{mg} / \mathrm{ml}$ were 3.21 and 2.16 .

According to the report of Lee et al. (2007) the reducing power of three edible mushrooms, Hypsizygus marmoreus, Agricus bisporus and Pleurotus ferulae were 0.99, 0.76 and 0.70 at 5 $\mathrm{mg} / \mathrm{ml}$ concentration. Consequently, the reducing power of $C$. indica was significantly higher and effective than the above mentioned mushrooms. Generally, the reducing properties are associated with the presence of reductones that exert antioxidant by breaking the free radical chain donating a hydrogen atom (Barros et al. 2007, Alam et al. 2012). 
Table 2. Reducing power of different extracts from the fruiting bodies of Calocybe indica.

\begin{tabular}{lcccc}
\hline Sample & \multicolumn{4}{c}{ Concentration $(\mathrm{mg} / \mathrm{ml})$} \\
\cline { 2 - 5 } & 1.0 & 2.0 & 4.0 & 8.0 \\
\hline Acetone extract & $0.622 \pm 0.03$ & $1.125 \pm 0.02$ & $1.581 \pm 0.05$ & $2.628 \pm 0.06$ \\
Methanol extract & $0.654 \pm 0.04$ & $1.318 \pm 0.15$ & $1.610 \pm 0.15$ & $2.825 \pm 0.03$ \\
Hot water extract & $0.515 \pm 0.02$ & $1.012 \pm 0.02$ & $1.310 \pm 0.04$ & $2.332 \pm 0.08$ \\
BHT & $3.212 \pm 0.49$ & - & - & - \\
TOC & $2.162 \pm 0.32$ & - & - & - \\
\hline
\end{tabular}

A value expressed as means $\pm \mathrm{Sd}(\mathrm{n}=3)$. - Not analyzed, BHT- Butylated hydroxytoluene and TOC- $\alpha$-tocopherol.

DPPH radical scavenging activity of acetone, methanol and hot water extracts from the fruiting bodies of $C$. indica ranged $33.71-91.75,31.75-87.46$, and $25.41-83.55 \%$, respectively (Fig. 1). The results indicated that DPPH scavenging activity of each extract was increased with increasing concentration. The acetone, methanol, and hot water extracts of $C$. indica showed good, moderate, and poor activities, respectively at the concentration tested. BHT, TOC and L-ascorbic were used as positive controls which showed excellent scavenging activities ranging from 85.25 98.74, $67.37-97.78$, and $96.74-98.23 \%$, respectively at the concentration of $0.125-2.0 \mathrm{mg} / \mathrm{ml}$.

Ethanolic extract from the fruiting bodies of $H$. marmoreus and A. bisporus on DPPH radicals showed the scavenging activities that ranged $46.6-68.4 \%$ at $5 \mathrm{mg} / \mathrm{ml}$ (Lee et al. 2007). The scavenging activities both cold and hot water extracts of the fruiting bodies and mycelia at 20 $\mathrm{mg} / \mathrm{ml}$ were 20.7 - 52.3 and 37.6 - 48.3, respectively. It revealed that the fruiting body of $C$. indica had more scavenging properties than those of the above mentioned edible mushrooms. Peroxy radicals are the major propagators of the autoxidation chain of fat, might have reacted by various extracts with free radical and thereby terminating the chain reaction (Frankel 1991). The natural antioxidant also showed the termination of free radical reaction.

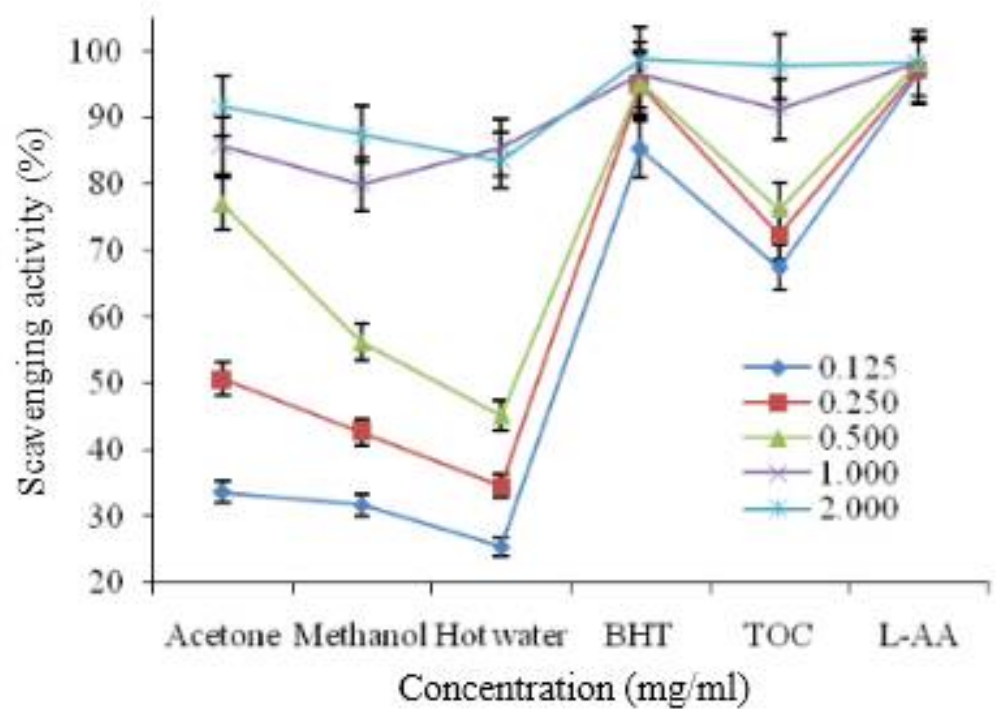

Fig. 1. Scavenging activity of various extracts from the fruiting bodies of Calocybe indica. A value expressed as means $\pm \mathrm{Sd}(\mathrm{n}=3)$. BHT- butylated hydroxytoluene, TOC- $\alpha$-tocopherol and L-AA-L-ascorbic acid. 
The chelating effect on ferros ions of acetone, methanol and hot water extracts from the fruiting bodies of $C$. indica at five different concentrations have been presented in Fig. 2. BHT and TOC were used as positive control for the investigation of ferrous ions. The results showed that the chelating aptitude of the tested extracts was increased with increasing concentration. The maximum chelating activity on ferrous ions $(87.10 \%)$ was recorded in methanol extract, while the lowest effect $(81.55 \%)$ was observed in TOC and hot water extract at the concentration of 1.0 $\mathrm{mg} / \mathrm{ml}$.

Chelating ability 42.6 and $45.8 \%$ were found in hot water extracts from the fruiting bodies of G. tsugae and A. cylindracea at the concentration of $20 \mathrm{mg} / \mathrm{ml}$ (Tsai et al. 2006). It refered that $C$. indica in ferrous ions had the same chelating abilities as that of H. marmoreus, while it showed more effectiveness than that of $G$. tsugae and A. cylindracea. Chelating agents may act as secondary antioxidants as they reduce the redox potential and thereby stabilizing the oxidized form of the metal ions. The various extracts from the fruiting bodies of $C$. indica has high ferrous ions chelating abilities. Therefore, it would be beneficial because ferrous ions are the most effective pro-oxidants in food system.

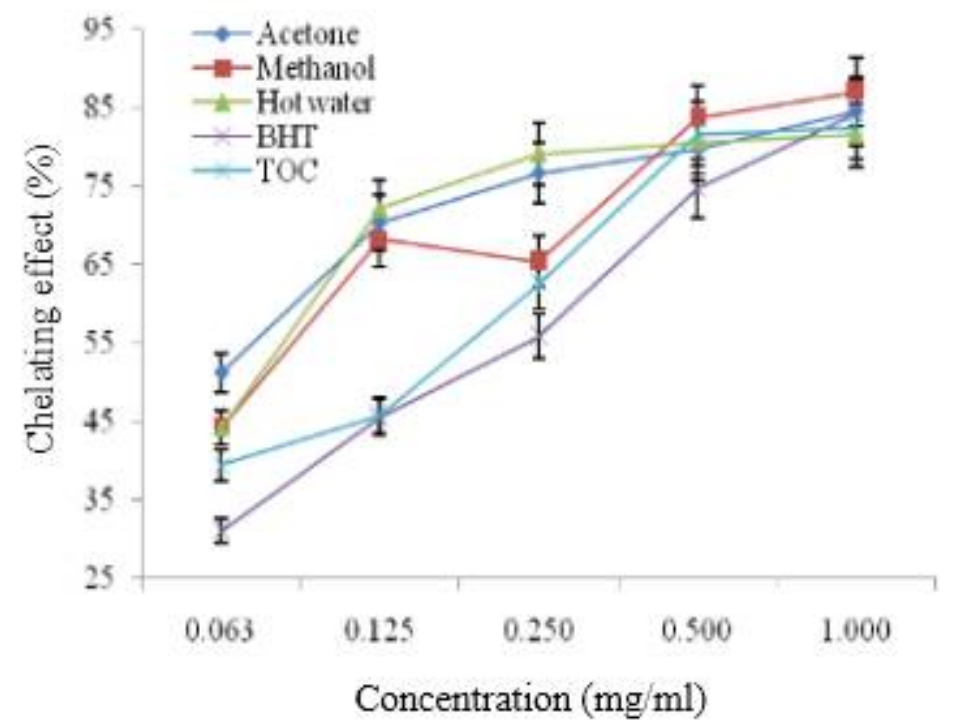

Fig. 2. Chelating effect of various extracts from the fruiting bodies of Calocybe indica. A value expressed as means \pm Sd $(n=3)$. BHT- butylated hydroxytoluene and TOC- $\alpha$-tocopherol.

Thirteen phenolic compounds such as biochanin-A, caffeic acid, chlorogenic acid, ferulic acid, formononetin, gallic acid, hesperetin, homogentisic acid, naringenin, naringin, protocatechuic acid, resveratrol and vanillin were detected from the fruiting bodies of $C$. indica (Fig. 3). Among the total concentration $(225 \mu \mathrm{g} / \mathrm{g})$ of phenolic compound, the highest and lowest concentrations were recorded for gallic acid $(29 \mu \mathrm{g} / \mathrm{g})$ and formononetin $(10 \mu \mathrm{g} / \mathrm{g})$, respectively. Similar findings were observed in some edible mushrooms (Kim et al. 2008) in which total concentration of phenolic compounds was $174 \mu \mathrm{g} / \mathrm{g}$. Phenolic compounds were present in different edible mushrooms in varying numbers ranging from $3-15$ and among them gallic acid is the most common. Thus, phenolic compounds would be used as an important indicator of antioxidant potentiality. There is a close relationship between antioxidant activity and phenolic content (Yoon et al. 2011). High levels of phenolic compounds were detected from the various edible and medicinal mushrooms 
that composed of one or more aromatic rings bearing one or more hydroxyl groups and exhibit extensive free radical-scavenging activities as hydrogen donors or electron-donating agents, and metal ion-chelating properties.
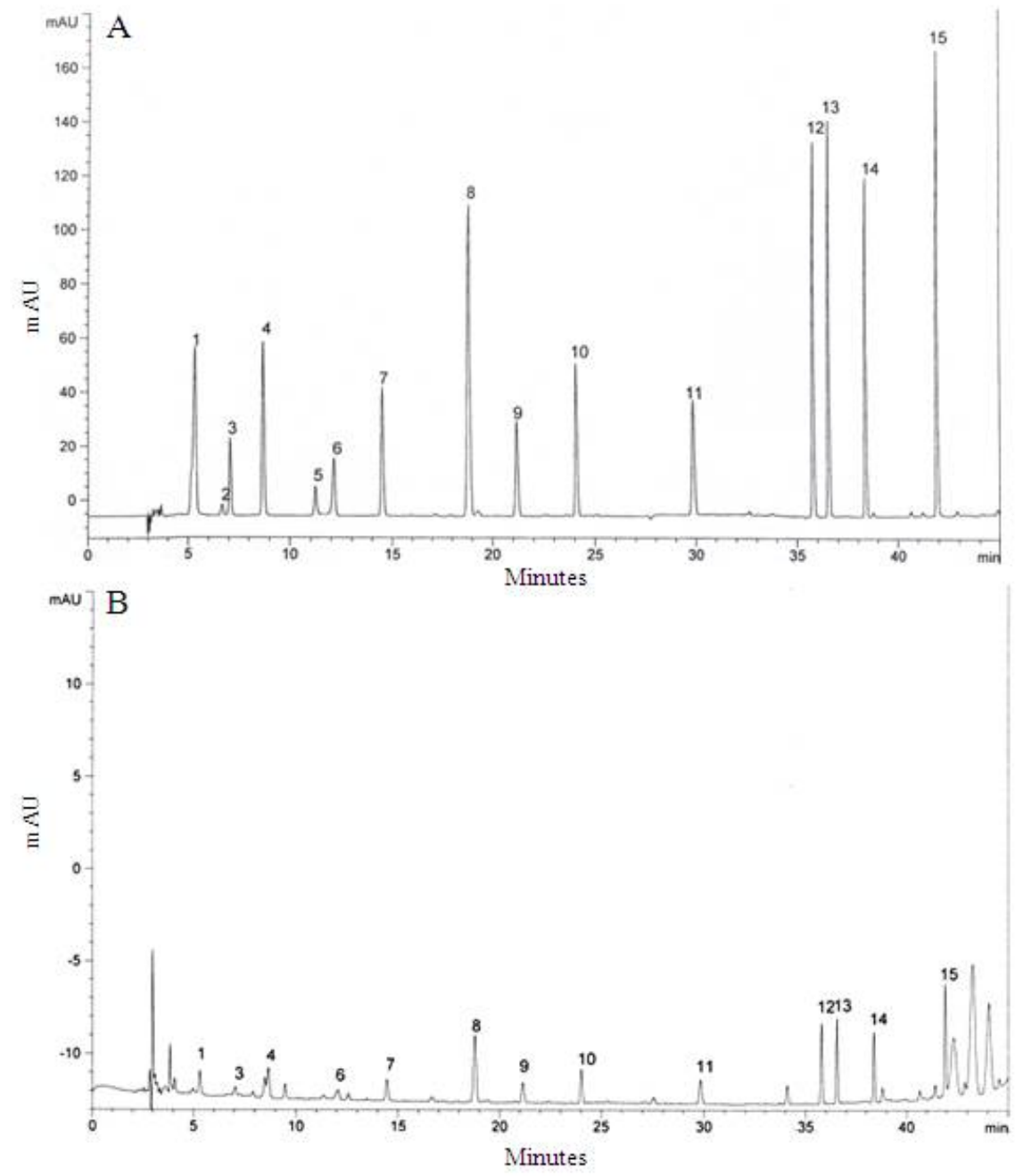

Fig. 3. High performance liquid chromatography of phenolic compounds. A - Standard mixture of 15 phenolic compounds, B - Calocybe indica extract. 1 - gallic acid, 2 - pyrogallol, 3 - homogentisic acid, 4 - protocatechuic acid, 5 - (+) catechin, 6 - chlorogenic acid, 7 - caffeic acid, 8 - vanillin, 9 - ferulic acid, 10 - naringin, 11 - resveratrol, 12 - naringenin, 13 - hesperetin, 14 - formononetin and 15 - biochanin-A.

Xanthine oxidase inhibitory activities of acetone, methanol and hot water extracts from the fruiting bodies of $C$. indica ranged $3.25-46.38,2.76-46.09$ and $1.78-45.03 \%$, respectively at the concentration of $0.5-8.0 \mathrm{mg} / \mathrm{ml}$. However, allopurinol showed the excellent xanthine oxidase inhibitory activity of $92.31-94.58 \%$ at the same concentrations. The results indicated that xanthine oxidase inhibitory activities of each extract increased with increasing concentration (Fig. 4). It revealed that the acetone and methanol extracts showed good results, while hot water extract revealed average activities at the tested concentration. Flavonoids are a group of polyphenolic 
compounds that possess xanthine oxidase inhibitory properties (Costantino et al. 1992). Thus, phenolic and flavonoid type of compounds in the extract would have contribution towards xanthine oxidase inhibition. Therefore, at the higher doses of extract, $\mathrm{XO}$ would be significantly inhibited.

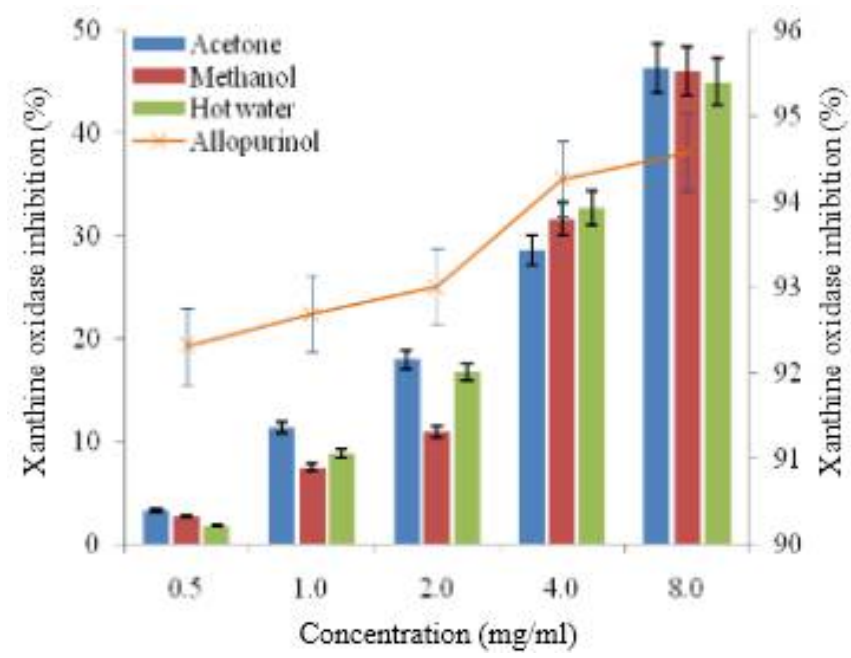

Fig. 4. Xanthine oxidase inhibition activity of various extracts from the fruting bodies of Calocybe indica. A value expressed as means $\pm S d(n=3)$.

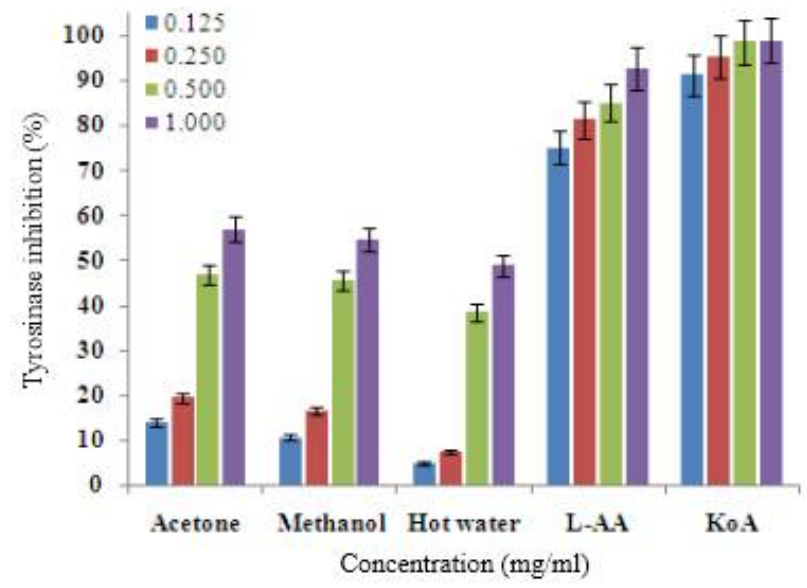

Fig. 5. Tyrosinase inhibition activity of various extracts from the fruiting bodies of Calocybe indica.

A value expressed as means $\pm \mathrm{Sd}(\mathrm{n}=3)$. L-AA- L-ascorbic acid and KoA-kojic acid.

Tyrosinase inhibitory activities of acetone, methanol, and hot water extracts from the fruiting bodies of $C$. indica ranged from $13.90-56.87,10.60-54.59$ and $4.86-48.82 \%$, respectively (Fig. 5). The results indicated that the tyrosinase inhibitory activities of each extracts were increased with increasing concentration and the acetone and methanol extracts showed good, while hot water showed moderate activities at the concentration tested. L-ascorbic acid and kojic acid used as positive control, showed the excellent tyrosinase inhibitory activities ranging from $75.12-92.74$ and $91.23-99.00 \%$, respectively at the concentration of $0.125-1.0 \mathrm{mg} / \mathrm{ml}$. 
The hydroxyl groups might be responsible for the inhibition of tyrosinase activities on the phenolic compounds of mushroom extracts that may form hydrogen bonds with an enzyme site leading to lower enzymatic activity. Some tyrosinase inhibitors bind to the tyrosinase active site through hydroxyl group, resulting in steric hindrance or altered conformation (Baek et al. 2008, Kim et al. 2008). Again, gallic acid acts as effective inhibitors of tyrosinase activity (Kubo et al. 2003, Momtaz et al. 2008). Moreover, the antioxidant activity may be one of the most important mechanisms for tyrosinase inhibitory activity. The experimental findings showed that $C$. indica have higher chelating effects than that of BHT and TOC on ferrous ions. Thirteen phenolic compounds were detected from the fruiting bodies of $C$. indica. The high phenolic content exhibited good antioxidant and antityrosinase activities. Therefore, the fruiting bodies of milky white mushroom may be suggested as a natural food source of antioxidants.

\section{Acknowledgements}

This research was supported by a research grant from the Ministry of Science and Technology, Government of the People's Republic of Bangladesh for capacity utilization programme in the financial year 2017-2018.

\section{References}

Alam N, Amin R, Khan A, Ara I, Shim MJ, Lee MW and Lee TS 2008. Nutritional analysis of cultivated mushrooms in Bangladesh - Pleurotus ostreatus, Pleurotus sajor-caju, Pleurotus florida and Calocybe indica. Mycobiology 36: 228-232.

Alam N, Yoon KN, Cha YJ, Kim JH, Lee KR and Lee TS 2011. Appraisal of the antioxidant, phenolic compounds concentration, xanthine oxidase and tyrosinase inhibitory activities of Pleurotus salmoneostramineus. Afr. J. Agric. Res. 6(6): 1555-1563.

Alam N, Yoon KN, Lee JS, Cho HJ and Lee TS 2012. Consequence of the antioxidant activities and tyrosinase inhibitory effects of various extracts from the fruiting bodies of Pleurotus ferulae. Saudi J. Biol. Sci. 19: 111-118.

Amin R, Khair A, Alam N and Lee TS 2010. Effect of different substrates and casing materials on growth and yield of Calocybe indica. Mycobiology. 38: 97-101.

Baek HS, Rho HS, Yoo JW, Ahn SM, Lee JY, Lee J, Kim MK, Kim DH and Chang IS 2008. The Inhibitory Effect of new hydroxamic acid derivatives on melanogenesis. Bull. Korean Chem. Soc. 29: 43-46.

Barros L, Ferreira MJ, Queiros B, Ferreira IC and Bapista P 2007. Total phenols, ascorbic acid, $\beta$-carotene and lycopene in Portuguese wild edible mushrooms and their antioxidant activities. Food Chem. 103: 413-419.

Costantino L, Albasini A, Rastelli G and Benvenuti S 1992. Activity of polyphenolic crude extracts as scavengers of superoxide radicals and inhibitors of xanthine oxidase. Planta Med. 58: 342-344.

Cuendet M, Hostettmann, Potterat O and Dyatmiko W 1997. Iridoid glucosides with free radical scavenging properties from Fagraea blumei. Helvetica. Chimica. Acta. 80: 1144-1152.

Dinis TC, Madeira VM and Almeida LM 1994. Action of phenolic derivatives (Acetaminophen, Salicylate, and 5-Amino Salicylate) as inhibitors of membrane lipid peroxidation and as peroxyl radical scavengers. Arch. Biochem. Biophys. 315: 161-169.

Diplock AT, Charleux JL, Crozier-willi G, Kok FJ, Rice-Evan C and Roberfroid M 1998. Functional food science and defence against reactive oxidative species. British J. Nutri. 80: 77-112.

Frankel EN 1991. Recent advances in lipid oxidation. J. Sci. Food Agric. 54: 495-511.

Gülçin I, Büyükokuroglu ME, Oktay M and Küfrevioglu OI 2003. Antioxidant and analgesic activities of turpentine of Pinus nigra Arn. subsp. pallsiana (Lamb.) Holmboe. J. Ethnopharmacol. 86: 51-58. 
Kim MY, Seguin P, Ahn JK, Kim JJ, Chun SC, Kim EH, Seo SH, Kang EY, Kim SL, Park YJ, Ro HM and Chung IM 2008. Phenolic compound concentration and antioxidant activities of edible and medicinal mushrooms from Korea. J. Agric. Food Chem. 56: 7265-7270.

Kubo I., Chen QX and Nihei KI 2003. Molecular design of antibrowning agents: Antioxidative tyrosinase inhibitors. Food Chem. 81: 241-247.

Lee YL, Yen MT and Mau JL 2007. Antioxidant properties of various extracts from Hypsizigus marmoreus. Food Chem. 104: 1-9.

Masuda T, Yamashita D, Takeda Y and Yonemori S 2005. Screening for tyrosinase inhibitors among extracts of seashore plants and identification of potent inhibitors from Garcinia subelliptica. Biosci. Biotechnol. Biochem. 69: 197-201.

Mau JL, Chang CN, Huang SJ and Chen CC 2004. Antioxidant properties of methanolic extracts from Grifola frondosa, Morchella esculenta and Termitomyces albuminosus mycelia. Food Chem. 87: 111118.

Momtaz S, Mapunya BM, Houghton PJ, Edgerly C, Hussein A, Naidoo S and Lall N 2008. Tyrosinase inhibition by extracts and constituents of Sideroxylon inerme L. stem bark, used in South Africa for skin lightening. J. Ethnopharmacol. 119: 507-512.

Sugimoto K, Nishimura T, Nomura K, Sugimoto K and Kuriki T 2004. Inhibitory effects of $\alpha$-arbutin on melanin synthesis in cultured human melanoma cells and a three-dimensional human skin model. Biol. Pharm. Bull. 27: 510-514.

Tsai SY, Huang SJ and Mau JL 2006. Antioxidant properties of hot water extracts from Agrocybe cylindracea. Food Chem. 98: 670-677.

Yoon KN, Alam N, Lee JS, Lee KR and Lee TS 2011. Detection of phenolic compounds concentration and evaluation of antioxidant and antityrosinase activities of various extracts from the fruiting bodies of Lentinus edodes. World Appl. Sci. J. 12(10): 1851-1859.

Zhou CX, Kong LD, Ye WC, Cheng CH and Tan RX 2001. Inhibition of xanthine and monoamine oxidases by stillbenoids from Veratrum taliense. Planta Medica. 67: 158-161. 